\title{
Magie d'album
}

\author{
Jean-Pierre Duprey
}

Petit cocktail de coeurs, en Octobre - un son malade suant sous la cascade - à chaque coup de fouet une biche s'affole (en rêve).

- Un hautbois et une flûte descendent l'horizon (en rêve).

- Le petit ours en peluche se trouvait là derrière le mausolée, il nous regarde.

- Ici veut-on abandonner la route? et les ronces et le fleuve forment deux taches rousses sur le soleil.

- Sous chaque buisson un couple soupire, il y a une petite fée en herbe qui demande son chemin.

(Cher petit monstre, quand tu ouvriras la bouche des bêtes grosses comme ça remonteront au galop tes oreilles - ne l'oublie pas! et si tu fermes les yeux c'est moi qui viendrai sangloter sur ta joue.)

- À la noce, la petite mariée roucoule sous son voile, à qui pense-t-elle? pas à moi bien sûr! Perdue ou envolée je ne ferai qu'en rire.

Mai 1946

Inédit en volume 